\title{
Electrospray Ionization-Tandem Mass Spectrometry Analysis of Peptides Derived by Enzymatic Digestion of Oxidized Globin Subunits: An Improved Method to Determine Amino Acid Substitution in the Hemoglobin "Core"
}

\author{
Toyofumi Nakanishi, Ayako Miyazaki, Masahiko Kishikawa, and \\ Akira Shimizu \\ Department of Clinical Pathology, Osaka Medical College, Takatsuki, Osaka, Japan
}

Tsuyoshi Yonezawa

Ikeda City Hospital, Ikeda, Osaka, Japan

\begin{abstract}
The determination of an amino acid substitution in the "core" region of abnormal hemoglobin is technically difficult and is time- and labor-intensive both by conventional and by mass spectrometry techniques. Underivatized subunits cleaved with trypsin and lysyl endopeptidase were analyzed by high-performance liquid chromatography-electrospray ionizationmass spectrometry. The core peptides showed a series of multiply charged ions of homo- and heterodimers. Abnormal peptides in the core region could be detected in dimeric form. The sequence of core peptides was determined by product ion spectra of the peptides from oxidized globin digested with trypsin and lysyl endopeptidase. Oxidation of cysteine residues to cysteic acids in the core region resulted in the strong promotion of $y$-series ions by product ion analysis with a tryptic peptide from apoprotein B-100 as previously reported by Burlet, Yang, and Gaskell ( $J$. Am. Soc. Mass Spectrom. 1992, 3, 337-344). These techniques were used to prove that substitution of an unstable hemoglobin, known as $\mathrm{Hb}$ Santa Ana ( $\beta 88$ leucine $\rightarrow$ proline), occurred in a patient with congenital hemolytic anemia. The tandem mass spectrometry analysis with oxidized globin digested with trypsin and lysyl endopeptidase offers a novel method to detect substitutions in the core region of hemoglobin. (J Am Soc Mass Spectrom 1996, 7, 1040-1049)
\end{abstract}

$\mathrm{M}$ any known hemoglobin variants are associated with apparent clinical manifestations, such as anemia, polycythemia, cyanosis and thrombosis, some of which are life-threatening [1]. Variant hemoglobin detection and identification are clinically important. However, identification of the variants usually requires complex and time-consuming chemical analysis. Since the 1981 pioneer work on variant identification introduced by Wada et al. [2] who used field desorption mass spectrometry, the procedures have been improved by secondary ion [3-5] or fast-atom bombardment [6, 7] mass spectrometry, and most recently by electrospray ionization (ESI) mass spectrometry [8-10] and tandem mass spectrometry [11-13]. However, in the case of amino acid substitu-

Address reprint requests to Dr. Akira Shimizu, Department of Clinical Pathology, Osaka Medical College, 2-7, Daigaku-cho, TakatsukiCity, Osaka, Japan, 569. tion in the "core" region of hemoglobin, the determination is rather complicated and time-consuming, even with these improved mass spectrometry techniques. Under the basic condition of tryptic digestion and also during preparation, the cysteine $-\mathrm{SH}$ group is oxidized to the disulfide, which forms homo- or heterodimeric molecules. We have reported previously [13] that the assignment of the ions in the electrospray ionization-mass spectrometry (ESI-MS) spectra of the tryptic digest of the nonderivatized globin, which covers the whole sequence of the $\alpha$ - and $\beta$-subunits, may offer a rapid diagnostic method to detect amino acid substitutions in the noncore region. For core peptides, it is possible to detect an ion of abnormal dimeric peptides by the difference of mass values. However, dimer peptides are hard to analyze by tandem mass spectrometry. For determination of amino acid substitutions, cysteine is derivatized by aminoethylation [8] or carboxyamidomethylation [14] for analysis by mass 
spectrometry. By aminoethylation, however, some tryptic peptides may be too small for mass spectrometry analysis. Some of the reagents for alkylation are carcinogenic and unstable under routine laboratory conditions, and because the buffers for the alkylation are not volatile, it takes rather a long time to remove the buffer and excess reagents.

Burlet and co-workers $[15,16]$ reported that oxidation of cysteine residues to cysteic acids in a tryptic peptide from apoprotein B-100 resulted in the strong promotion of $y$-series ions, and both the absolute and relative abundances of this fragment type were increased in the measurement by hybrid sectorquadrupole instruments that involve low collision energy. They explained that the formation of multiple numbers of the $y_{n}$ series of ions (nomenclature for fragment ions according to Bieman [17]) is promoted by a gas-phase interaction between the C-terminal basic amino acid residues and cysteic acid residues, which reduces the propensity for protonation exclusively at the C-terminal arginine or lysine. The oxidation of globin may be suitable for the determination of amino acid substitutions in the core region by tandem mass spectrometry analysis. The reagents for oxidation (formic acid and hydrogen peroxide), are removed easily by evaporation. If we can obtain reliable spectra by tandem mass spectrometry with oxidized peptides, performic acid oxidation might be the best choice of derivatization method for core peptides. Herein, we analyzed the peptides from oxidized globin by triplestage quadrupole mass spectrometry. To obtain high yields of core region peptides, globin or its subunits were cleaved with both trypsin and lysyl endopeptidase, which cleaves the C-terminal amide bond of lysine and the bonds resistant to trypsin, such as the bond between lysine and aspartic acid or the Cterminal bond of Asp-Lys [18]. By this improved procedure, we determined an amino acid substitution in the core region of an abnormal hemoglobin that had the same structure as $\mathrm{Hb}$ Santa Ana ( $\beta 88$ leucine $\rightarrow$ proline) [19].

\section{Experimental}

\section{Materials}

Hemoglobin was obtained from normal healthy adults and from a Japanese patient with congenital hemolytic anemia.

\section{Preparation of peptides}

The hemoglobin solution and globin were prepared by the method previously described [20-22]. The normal and abnormal $\beta$-subunits were separated by highperformance liquid chromatography (HPLC) in accordance with the report of Schroeder et al. [23] by using a $4.6-\mathrm{mm} \times 250-\mathrm{mm}$ reverse phase column (Vydac $\mathrm{C}_{4}$ ). The gradients were formed between solvent A $(8: 2$ mixture of aqueous $0.1 \%$ trifluoroacetic acid and $0.1 \%$ trifluoroacetic acid in acetonitrile) and $B$ (these solutions in a ratio of $1: 9$ ). The flow rate was $1 \mathrm{~mL} \mathrm{~min}^{-1}$. Globin was oxidized at $-5^{\circ} \mathrm{C}$ with performic acid in accordance with the method of Hirs [24].

The peptides were prepared by tryptic digestion alone and by cleavage with combinations of two enzymes. One combination was trypsin and lysyl endopeptidase and the other was trypsin and V8 protease. Intact globin was cleaved with trypsin in 0.1-M ammonium bicarbonate $(\mathrm{pH} 8.4)$ for 24 h. Oxidized globin or intact $\beta$-chain were cleaved with trypsin and lysyl endopeptidase in $0.1-\mathrm{M}$ ammonium bicarbonate (pH 8.4). After tryptic digestion for $1 \mathrm{~h}$ at $37^{\circ} \mathrm{C}$, lysyl endopeptidase was added to the reaction mixture, which was incubated for an additional $23 \mathrm{~h}$ at $37^{\circ} \mathrm{C}$. For the combination of trypsin and V8 protease, protein was cleaved with trypsin in $0.1-\mathrm{M}$ ammonium bicarbonate ( $\mathrm{pH} \mathrm{8.4)} \mathrm{for} 24 \mathrm{~h}$ and the reaction mixture was lyophilized. V8 protease was then added to the tryptic digests dissolved in 0.1-M ammonium bicarbonate ( $\mathrm{pH}$ 8.8) and digestion was continued for an additional $24 \mathrm{~h}$ at $37^{\circ} \mathrm{C}$. For each enzyme, the concentration of the protein was $1 \mathrm{mg} \mathrm{mL} \mathrm{m}^{-1}$ and the ratio of enzyme to protein was $1: 100(w / w)$. The reaction mixture was lyophilized and redissolved in distilled water; this step was repeated four times to remove trace amounts of ammonium bicarbonate. For preparation of samples, $\sim 0.1 \mathrm{~mL}$ of blood was used and $100 \mathrm{mg}$ of lyophilized globin or separated subunit was digested with the enzymes. L-(tosylamido 2phenyl) ethyl-chloromethyl ketone (TPCK) trypsin was purchased from Worthington Biochemical Corp. (Freehold, NJ; lot 33K996). Lysyl endopeptidase from Achromobacter lyticus was purchased from Wako Pure Chemical Industries (Osaka, Japan; lot YLR9326). Protease V8 from Staphylococcus aureus was purchased from ICN Biomedicals Inc. (Costa Mesa CA; lot 035A).

\section{Mass Spectrometry}

ESI mass spectra were obtained on a TSQ-7000 triplestage quadrupole mass spectrometer (Finnigan MAT, San Jose, CA) equipped with an electrospray ion source. Samples were introduced into the ion sources by infusion with a Harvard Apparatus (South Natick, MA) pump by using a solvent of $50 \%$ methanol in water that contained $1 \%(\mathrm{v} / \mathrm{v})$ acetic acid, at a flow rate of $3 \mu \mathrm{L} \min ^{-1}$. The amount of digest consumed for each analysis was $100 \mathrm{~mL}$ of $\sim 10 \mathrm{pmol} \mu \mathrm{L}^{-1}$ (the $\sim 10$ pmol corresponds to $\sim 320 \mathrm{ng}$ of globin and $\sim 160 \mathrm{ng}$ of $\beta$-subunit) in the methanol $(50 \%)$ and acetic acid (2\%) solution. Intact globin also was analyzed with the same amount dissolved in the same solution.

Digests also were applied to a microcapillary column connected to the ion source. A silica-based microcapillary HPLC column (Vydac $C_{18}, 0.5 \mathrm{~mm} \times$ $150 \mathrm{~mm} ; 300 \AA$; 5 mm; Michrom Bioresources Inc., 
Pleasanton, CA) was used. Peptides dissolved in acetonitrile-water $(2: 98)$ that contained $0.1 \%$ trifluoroacetic acid were injected and were eluted with a gradient of 2-55\% acetonitrile that contained $0.08 \%$ trifluoroacetic acid over $45 \mathrm{~min}$ at a flow rate of $50 \mu \mathrm{L} \mathrm{min}{ }^{-1}$. For each liquid chromatography-mass spectrometry (LC-MS) analysis, $10 \mu \mathrm{L}$ of $\sim 10 \mathrm{pmol}$ $\mu \mathrm{L}^{-1}$ (the $\sim 10$ pmol corresponds to $\sim 160 \mathrm{ng}$ of $\beta$-chain) was injected.

For ESI-MS, the scanning range was $m / z$ 50-2500 in $3 \mathrm{~s}$ and the octapole offset potential was set at $3 \mathrm{~V}$. Intact globin and tryptic peptides of underivatized globin mixture from infusion and peptides of underivatized normal and abnormal $\beta$-subunits cleaved by trypsin and lysyl endopeptidase through HPLC were analyzed by using the foregoing scanning conditions. Digests of oxidized globin were analyzed by tandem mass spectrometry by using the system HPLC-ESI-MS-CID-MS (collision-induced dissociation mass spectrometry). To measure the product ion spectra, the precursor peak width was increased to $m / z \sim 4$, and the collision cell voltage was set at 30-55 V; the scanning range was $m / z 50-2500$ for the second mass analyzer and the octapole offset potential was set as before. For ion fragmentation in the electrospray source [25], the scanning range and time were the same as normal scanning stated previously and the octapole offset potential was set at 15-25 V. Calibration was performed by using the peptide Met-ArgPhe-Ala and horse apo-myoglobin for all procedures. The structure of the peptides was assigned by tandem mass spectra, in accordance with the principles introduced by Hunt et al. [26], by using a program named Peptide Matching and Interpretation (ICIS and Biotech, Version 8.0, Finnigan MAT). In tandem mass spectra, the minimum acceptable signal-to-noise ratio was set at 3 . The amino acid sequence of normal hemoglobin and the nomenclature of the tryptic peptides were according to Hilse and Braunitzer [27] and Guidotti et al. [28] ( $\beta$ T indicates the tryptic peptide of the subunit; the number is the order from the amino terminus in the present paper).

\section{Results}

Figure 1 shows a deconvoluted spectrum from a massto-charge ratio spectrum of globin prepared from a patient with congenital hemolytic anemia. The ion of the $\beta$-subunit prepared from the patient's blood showed a split peak: the average molecular weight of one peak was $15854.0 \pm 1.3$ and the other was 15868.3 \pm 1.2 ; the mass difference between the two components was estimated 12-16 u. Therefore, an amino acid substitution in the $\beta$-subunit of the abnormal hemoglobin was suspected. The amino acid substitution was determined by the following four steps:

1. ESI-MS of tryptic digests of a mixture of all globins $(\alpha$, normal, and abnormal $\beta$ ).

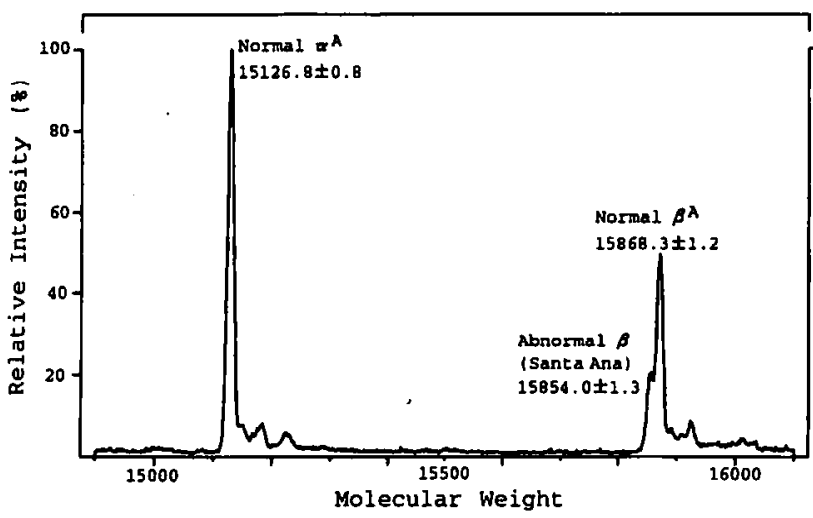

Figure 1. A mass spectrum deconvoluted from a mass-to-charge ratio spectrum of globin prepared from a patient with congenital hemolytic anemia. The values are given as the average plus or minus standard deviation of the calculated values of each ion.

2. High-performance liquid chromatography-electrospray ionization-mass spectrometry (HPLC-ESI-MS) of separated normal and abnormal $\beta$-subunits digested with trypsin and lysyl endopeptidase.

3. High-performance liquid chromatography-electrospray ionization-tandem mass spectrometry (HPLC-ESI-MS/MS) of mixture of all oxidized globin.

4. Electrospray ionization-tandem mass spectrometry (ESI-MS/MS) of abnormal $\beta$-subunit digested with trypsin and V8 protease.

The first step was for screening. The globin mixture, which contained $\alpha$ - and $\beta$-subunits from normal and abnormal components, were cleaved with trypsin and the peptides were analyzed by ESI-MS by sample loading through an infusion pump. Abnormal peptides could not be found at this step. All peptides except the core region showed the expected mass-to-charge ratio values. In the case of substitution in a noncore region, abnormal peptides should be detected in this step as we reported previously [13]. In the second step, the separated normal and abnormal $\beta$-subunits that were not oxidized were cleaved with trypsin and lysyl endopeptidase and the digests were analyzed by ESI-MS through a microcapillary HPLC. A series of ions of multiply charged $\beta$ T10 and $\beta$ T12 homodimers and $\beta$ T10 $-\beta$ T12 heterodimer were observed in mass chromatograms obtained by LC-MS of peptides of normal $\beta$-subunits (Figure 2a). Singly charged ions of dimer peptides were outside the scanning range of up to $\mathrm{m} / \mathrm{z}$ 2500 . The mass-to-charge ratio of doubly charged ions of homodimers and singly charged ions of monomer peptides were slightly different. Theoretically, the former is $1.0 \mathrm{u}$ smaller than the latter. Observation of the series of multiply charged ions shown in the insets of Figure 2 confirms that these ions are generated from dimer peptides. The mass chromatograms of digests of abnormal $\beta$-subunits showed ion peaks of $\beta \mathrm{T} 12$ homodimer, but no ion peaks of $\beta$ T10 homodimer or 
a)

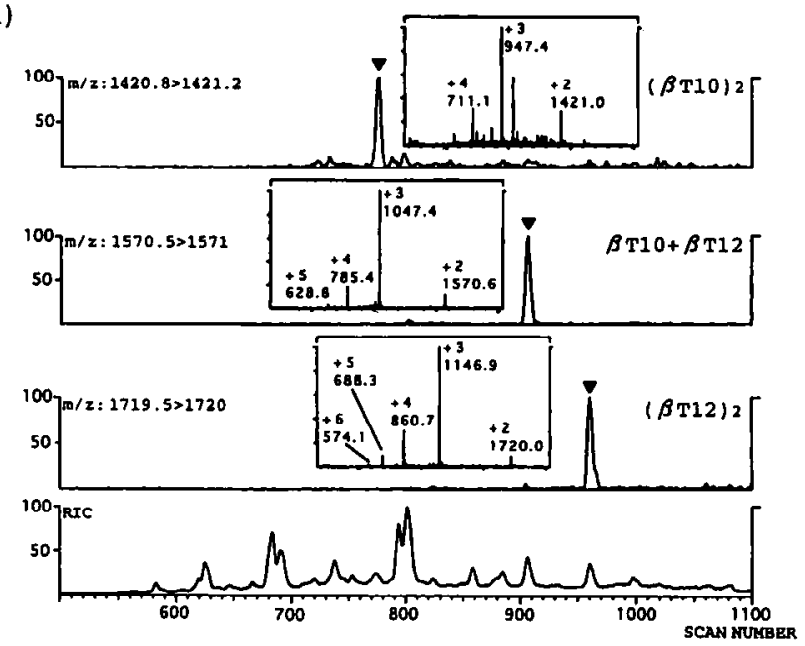

b)

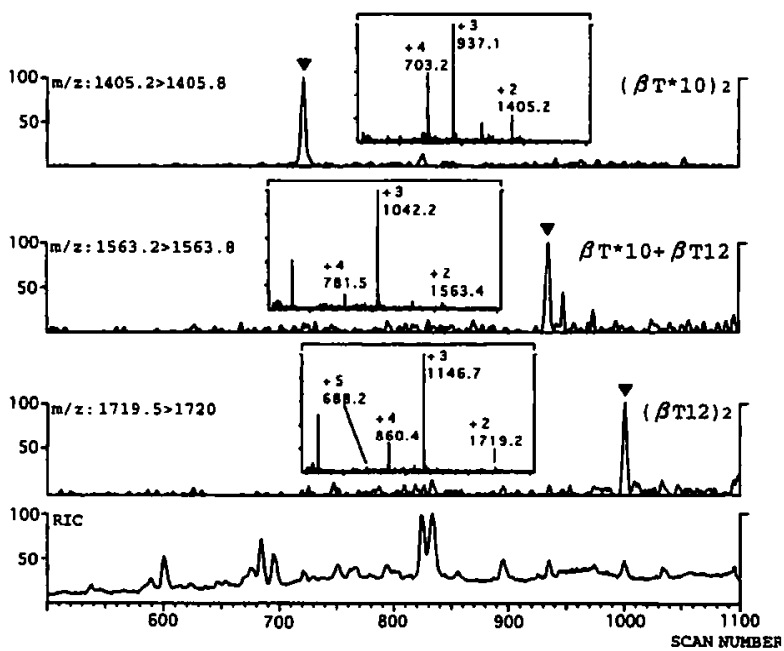

Figure 2. Reconstructed selected ion chromatograms and total ion chromatogram by microcapillary HPLC-ESI-MS of peptides digested with trypsin and lysyl endopeptidase from underivatized $\beta$-subunits of an abnormal hemoglobin in comparison with normal counterparts. The ions of interest were selected from the total ion chromatogram. (a) normal control. Traces for selected ions, $m / z 1421.0 \pm 0.3$ for doubly charged $\beta T 10$ dimers, $m / z$ $1570.8 \pm 0.3$ for doubly charged heterodimer of $\beta$ T10 and $\beta$ T12, and $m / z \quad 1719.8 \pm 0.3$ for doubly'charged $\beta$ T12 dimers are shown. By the analysis of peptides from abnormal $\beta$-subunit, the former two ions were not detected. Therefore, the ions that correspond to 12-16 $\mathrm{u}$ less than the normal counterparts were plotted. (b) The abnormal ion peaks at $m / z 1405.5 \pm 0.3$ for doubly charged abnormal $\beta$ T10 dimer and $m / z 1563.5 \pm 0.5$ for doubly charged abnormal $\beta \mathrm{T}^{*} 10$ and normal $\beta$ T12 connected by a disulfide bridge. The scale of the relative abundance for the selected ions is normalized in the chromatogram of each selected ion. The ESI spectra of each peak marked by an arrow are shown in insets.

$\beta$ T10- $\beta$ T12 heterodimer. The search by mass chromatography to find ion peaks of 12-16 u less than the normal $\beta$ T10 peak revealed a prominent ion peak of abnormal $\beta$ T10 ( $\left.\beta \mathrm{T}^{*} 10\right)$, which was $16 \mathrm{u}$ less than the normal $\beta$ T10 peak. These mass chromatograms are shown in Figure $2 b$.

In the third step, the mixture of globin derived from a normal individual and globin from a patient who carried a variant were oxidized by performic acid and cleaved with trypsin and lysyl endopeptidase. The peptides that contained cysteic acids were analyzed by microcapillary HPLC-ESI-MS/MS. Figure 3 shows mass chromatograms from microcapillary HPLC-ESIMS analysis of peptides digested with trypsin and lysyl endopeptidase from an oxidized mixture of globins derived from a patient. Singly charged ions of oxidized peptides of $\beta \mathrm{T}^{*} 10, \beta \mathrm{T} 10$, and $\beta \mathrm{T} 12$, and doubly charged ion of oxidized $\alpha \mathrm{T} 12$ were monitored. The ions at $m / z$ 1509-1510 for $\alpha \mathrm{T} 12$, at $m / z$ 1470-1471 for $\beta$ T10, and at $m / z 1768.5-1769.5$ for $\beta$ T12 were found in both the normal and the abnormal cases, but the ion at $m / z$ 1454-1455, which corresponds to the singly charged ion of oxidized $\beta \mathrm{T}^{*} 10$, was found only in the abnormal case.

Figure 4 shows the product ion spectra of these ions. Doubly charged precursor ions, $\mathrm{m} / \mathrm{z} 727.4$ and 735.8 were used for collision-induced dissociation (CID) spectra measurements. The $y$-series ions were relatively clear in these spectra. The product ion spectrum of $m / z 735.8$ (which corresponds to singly charged 1470.6; Figure 4a) indicated an assignment to oxidized $\beta$ T10 of normal globin. The product ion spectra of precursor ions at $\mathrm{m} / \mathrm{z} 735.8$ (Figure $4 \mathrm{a}$ ) and 727.4 (Figure $4 \mathrm{~b}$ ) included common y ions below $\mathrm{m} / \mathrm{z} 880$ (i.e., $y_{1}-y_{7}$ ). These ions correspond to the $y$ ions that show the sequence ( $\beta 89-95)$ Ser-Glu-Leu-His-cysteic

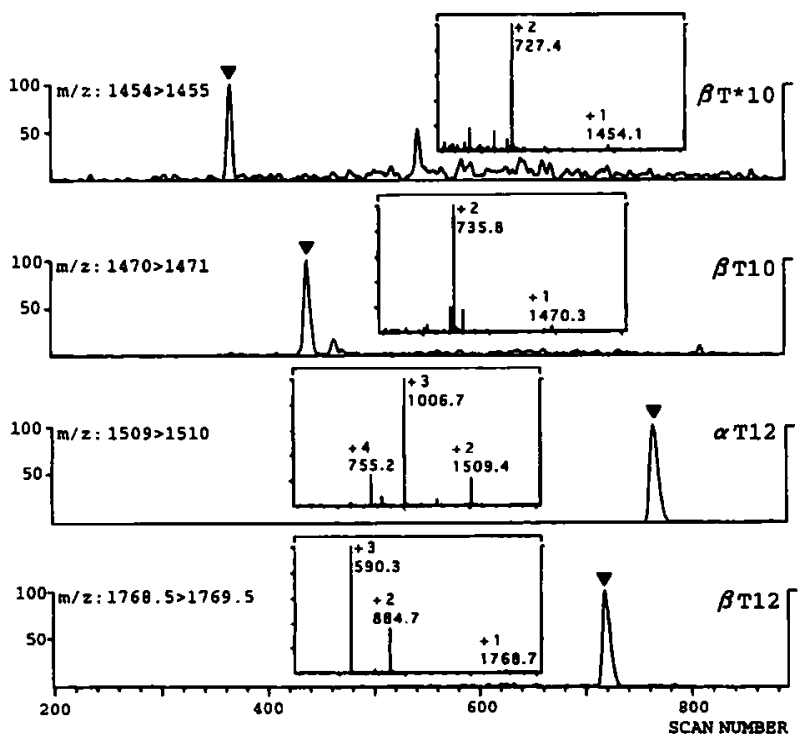

Figure 3. Reconstructed selected ion chromatograms of microcapillary HPLC-ESI-MS of peptides digested with trypsin and lysyl endopeptidase from oxidized globin derived from a patient who carries a mixture of normal and abnormal hemoglobin. The ions of interest were selected from the total ion chromatogram. Traces for selected ion, $m / z 1454.5 \pm 0.5$ for singly charged abnormal oxidized $\beta T^{*} 10, m / z \quad 1470.5 \pm 0.5$ for singly charged oxidized normal $\beta$ T10, $m / z 1509.5 \pm 0.5$ for doubly charged oxidized normal $\alpha T 12$, and $m / z \quad 1769.0 \pm 0.5$ for singly charged oxidized normal $\beta$ T12 are shown. The scale of the relative abundance for the selected ions is normalized in the chromatogram of each selected ion. ESI spectra of each peak marked by an arrow are shown in insets. 
acid-Asp-Lys. The ion $y_{8}$ at $m / z 992.5$ in the spectrum of normal peptide (Figure 4a) was not observed in the spectrum of the variant peptide (Figure $4 \mathrm{~b}$ ). Instead, a prominent ion was observed at $m / z 976.4$ in the spectrum of Figure $4 \mathrm{~b}$. The mass difference of these ions was $16.1 \mathrm{u}$. The ions that correspond to $\mathrm{y}_{9}, \mathrm{y}_{10}$, and $\mathrm{y}_{11}$ in the spectrum of the variant were identical to those in the normal spectrum if we subtract $16 \mathrm{u}$ from the mass number of $y$-series ions larger than $m / z \quad 970$ in the spectra of normal $\beta$ T10. These ions show the $\beta 85-87$ sequence Phe-Ala-Thr. The difference of the two prominent ions of $97.3 \mathrm{u}$ observed in the spectra of variant peptide ( $\mathrm{m} / \mathrm{z} 976.6$ and 879.3 ) corresponds to the proline residue. Therefore, we concluded that the

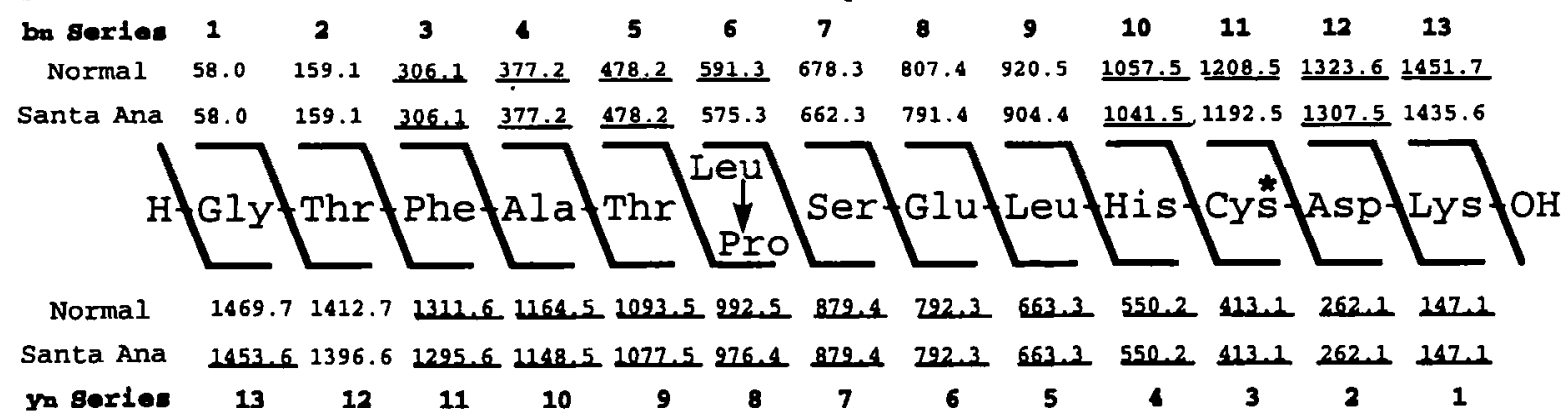

a)
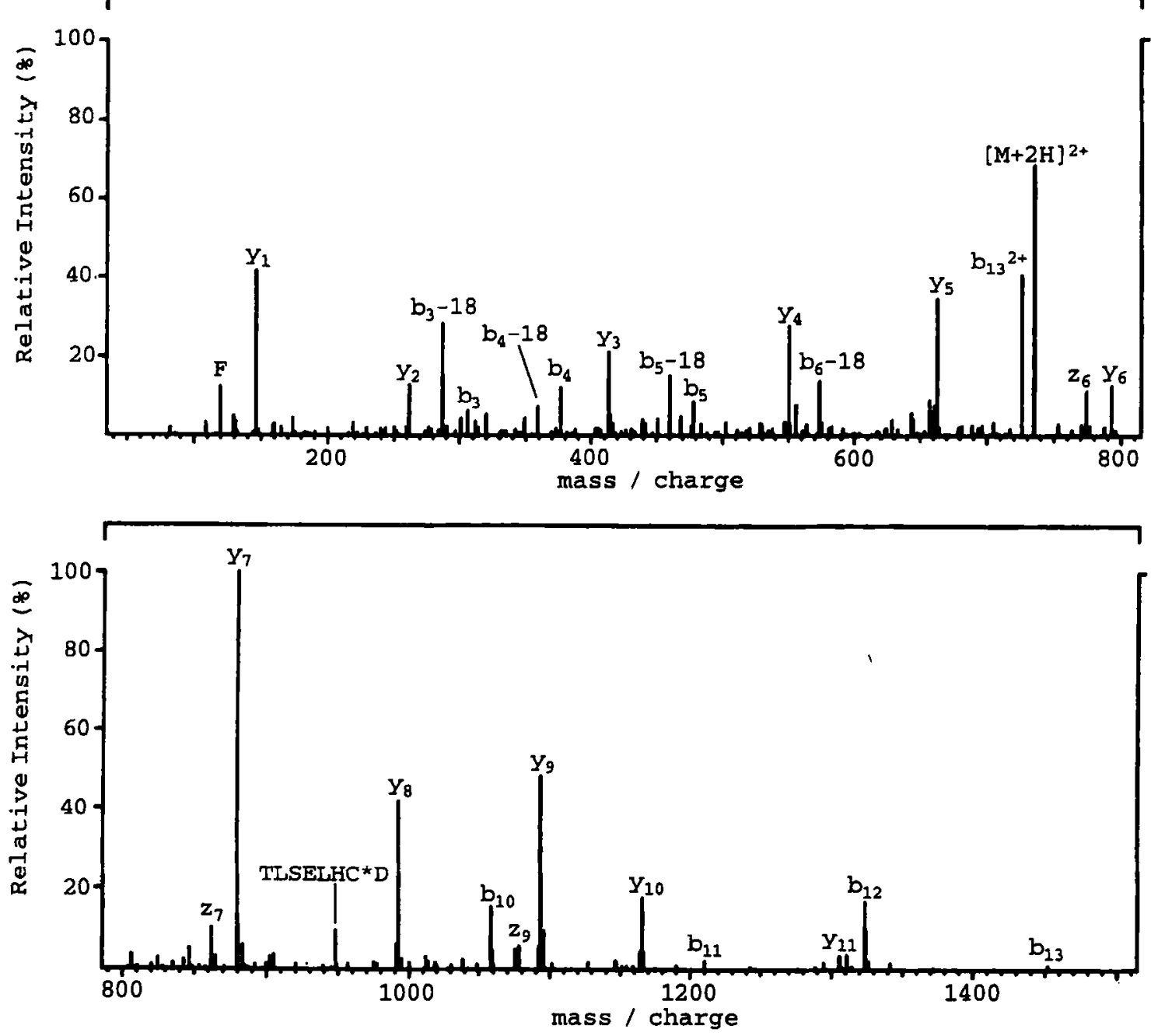

(Figure continued on next page)

Figure 4. Product ion spectra from CID of (a) $m / z 735.8$, the doubly charged precursor ion of oxidized $\beta$ T10 (normal), and (b) $m / z$ 727.4, the doubly charged precursor ion of oxidized $\beta^{*}$ T10 (abnormal). The top section of the figure shows the proposed amino acid sequence and expected $\mathrm{y}_{n}$ and $\mathrm{b}_{n}$ fragment ion masses; those values underlined were detected in CID spectra. Cys ${ }^{*}$ indicates cysteic acid. 
b)
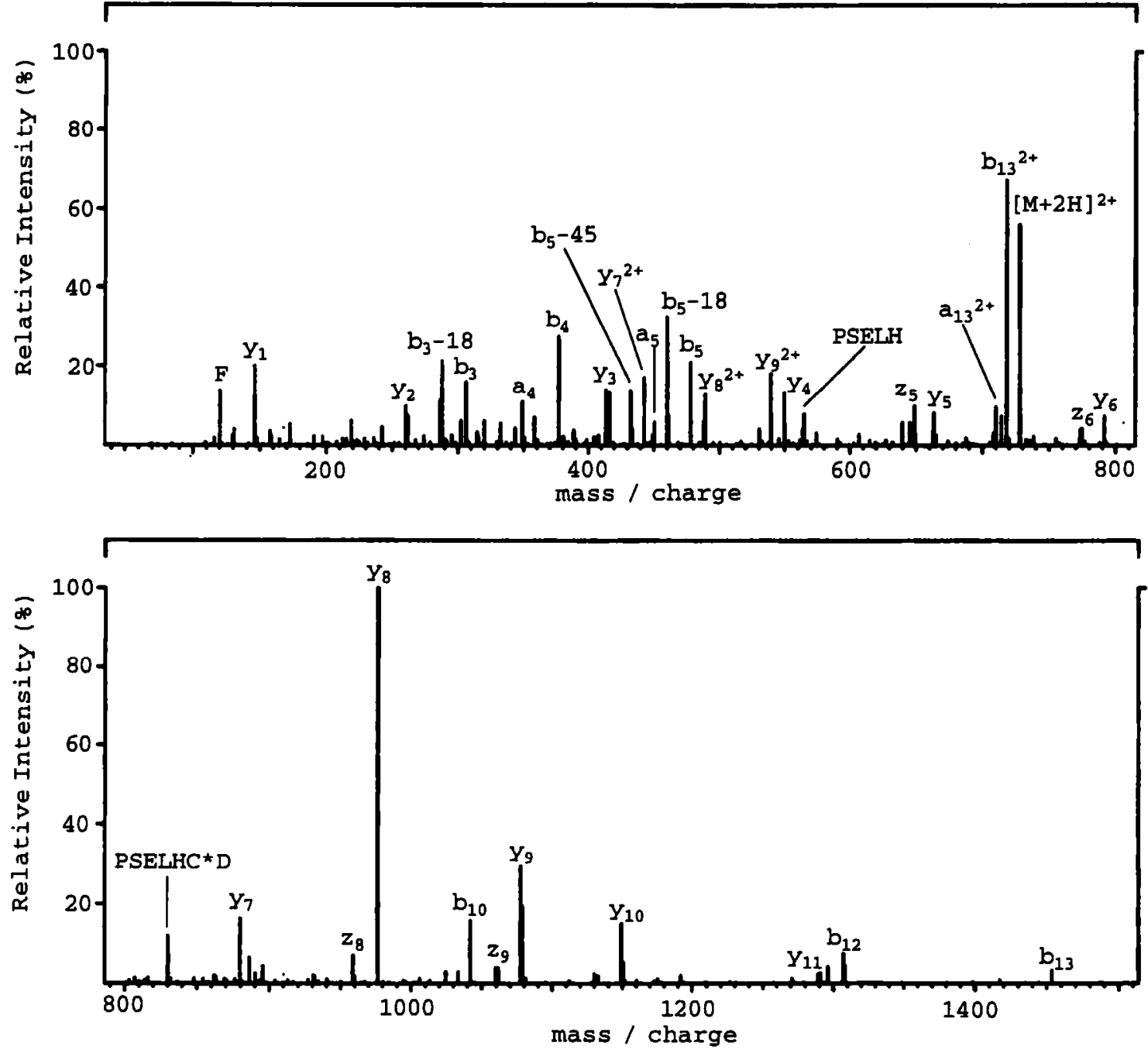

Figure 4. (Continued)

leucine at the 88th position of the normal $\beta$-chain is substituted by proline in the hemoglobin we analyzed, as in $\mathrm{Hb}$ Santa Ana [19].

The product ion spectrum of the precursor ion at $m / z 727.4$, which corresponds to $\beta \mathrm{T}^{*} 10\left([\mathrm{M}+2 \mathrm{H}]^{2+}\right)$, showed a prominent product ion at $m / z 976.4\left(\mathrm{y}_{8}\right.$; Figure $4 \mathrm{~b}$ ). This ion also could be generated in the ion source and we used it for the $\mathrm{MS}^{3}$ experiment (ion source CID). Figure 5 shows the product ion spectrum of a precursor ion of $m / z 976.4$ generated by ion source CID. The spectrum shows the $y_{n}{ }^{-}$as well as $\mathrm{b}_{n}$-series ions of the abnormal $y$ ion $\beta 88-95$ (Pro-SerGlu-Leu-His-cysteic acid-Asp-Lys). It was shown previously that fragmentation of the peptide bond that involves the proline amino group to yield the corresponding $y$ ion is more likely to occur than with other amino acid residues [26].

Abnormal $\beta$-subunit without oxidation was digested by trypsin and V8 protease and the digests were analyzed by ESI-MS by infusion loading. This experiment was performed to confirm the result of mass spectrometry analysis with oxidized materials. By using the knowledge of the possible substitution Leu $\rightarrow$ Pro at $\beta 88$ and the specificity of these enzymes, an ion of expected mass was examined selectively. The mass value and partial information from the product ion spectrum of an ion of $\mathrm{m} / \mathrm{z} 809.6$ suggested that the ion corresponded to the peptide from amino acid residues 83-90 of the abnormal $\beta$ chain. A major product ion of the peptide was at $m / z$ $331.5\left(y_{3}\right)$. This ion was obtained by ion source CID and was analyzed by tandem mass spectrometry. The spectrum showed that the sequence corresponded to Pro-Ser-Glu. The spectrum is not shown, but is available on request.

Product ion mass spectra of precursor ions of $\mathrm{m} / \mathrm{z}$ 1006.7 , a triply charged ion of normal oxidized $\alpha \mathrm{T} 12$, and $m / z 884.7$, a doubly charged ion of oxidized 

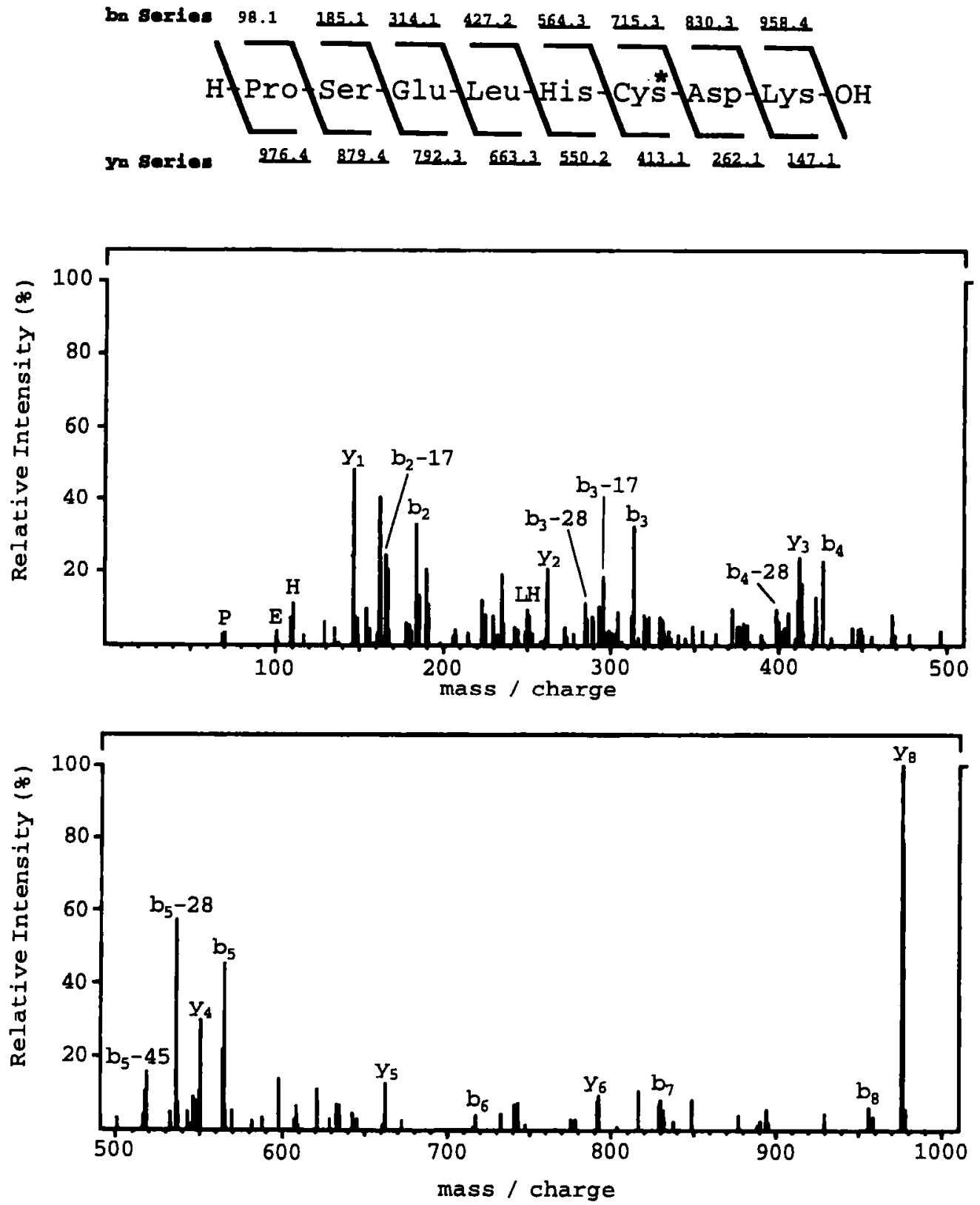

Figure 5. Product ion spectrum of a precursor ion of $\mathrm{m} / \mathrm{z} 976.6$ obtained by ion source CID. The ion was a product ion of the abnormal oxidized peptide $\beta \mathrm{T}^{*} 10$ as shown in Figure $4 \mathrm{~b}$ and was generated in the ion source by using a higher octapole offset (20 V). The ion was analyzed by usual CID activation.

$\beta$ T12, are shown in Figure 6. The sequence of most amino acids in these peptides could be determined from the spectra.

\section{Discussion}

The analysis of nonoxidized peptides by HPLC-ESI-MS revealed a dimeric abnormal peptide $\beta \mathrm{T}^{*} 10$. For sequence determination, the oxidized globin was digested with trypsin and lysyl endopeptidase and the HPLC-ESI-MS/MS of the digests clearly showed the ions of oxidized peptides in the core region. The fragment ions of the $y$ series in product ion spectra of peptides that contain cysteic acid were prominent as previously reported with an apoprotein peptide by Burlet et al. $[15,16]$. Here, this procedure was successfully applied to determine the substitution of leucine by proline at the 88th position of $\beta$-chain, as seen in $\mathrm{Hb}$ Santa Ana [19]. A fragment ion that represents cleavage of the peptide bond that involves the proline amino group yielded the corresponding strong $y$ ions [26]. Fragmentation by application of higher voltage in 
the intermediate pressure region of the ion source enabled the ion with $\mathrm{N}$-terminal proline to be selected and analyzed by the usual tandem mass spectrometry.

These procedures are rather simple and reliable, and to our knowledge, this is the first report of tandem mass spectrometry analysis of oxidized peptides for determination of the hemoglobin variant. In our experiment with normal and abnormal hemoglobin, all peptides that contain cysteic acid, that is, $\alpha \mathrm{T} 12, \beta \mathrm{T} 10$, and $\beta \mathrm{T} 12$, showed strong precursor ions and clear product ion spectra. In addition to cysteine, methionine and tryptophan also are oxidized by the conditions we employed. These three core region peptides do not contain methionine or tryptophan. The abundance of ions of peptides that contain oxidized methionine ( $\alpha \mathrm{T} 5$, $\alpha \mathrm{T} 9$, and $\beta \mathrm{T} 5)$ were strong and the CID spectra also clearly showed the $y$-series ions. The oxidation of tryptophan may result in the formation of a heterogeneous structure of tryptophan-containing peptides. Therefore,

a)
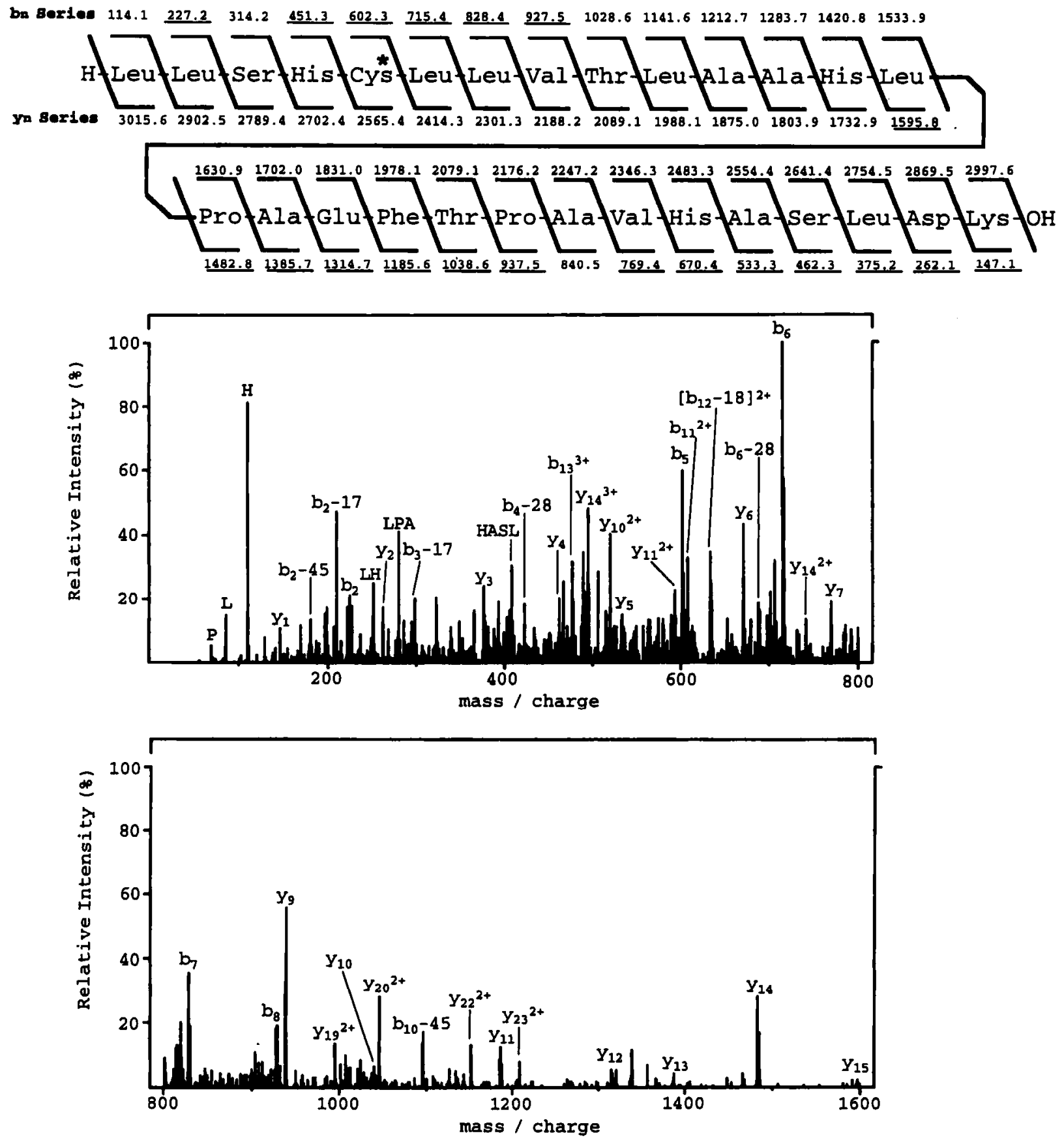

(Figure continued on next page)

Figure 6. Product ion spectra from CID of (a) $m / z$ 1006.7, the triply charged precursor ion of normal oxidized $\alpha$ T12, and (b) $m / z$ 884.7 , the doubly charged precursor ion of oxidized $\beta T 12$. 
b)
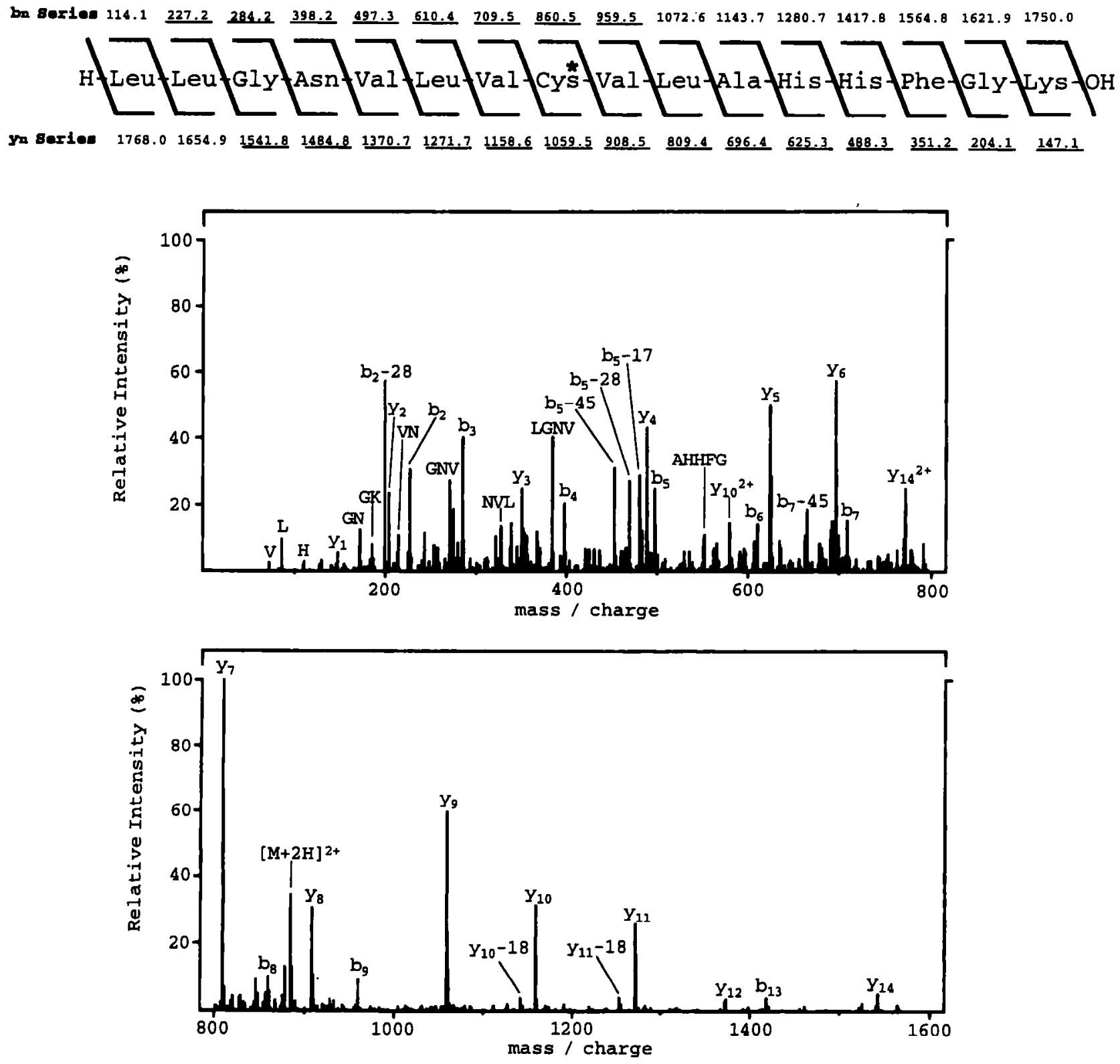

Figure 6. (Continued)

for structural study of the noncore region, peptides prepared from nonoxidized globin must be analyzed. We have reported that tandem mass spectrometry analysis of tryptic peptides of nonderivatized globin is suitable for the study of amino acid substitution [13]. However, the quality of product ion spectra of some peptides, especially cysteine-containing peptides, was not high enough to verify the sequence. The analyses of peptides from intact globin and peptides from oxidized globin are complementary. By the analysis of both digests, high quality tandem mass spectra may cover the whole sequence of $\alpha$ - and $\beta$-subunits.

\section{Acknowledgments}

This work was supported by a 1994-1995 grant (C-06807180) in aid for scientific research from the Ministry of Education, Science and Culture of Japan.

\section{References}

1. Weatherall, D. J.; Clegg, J. B.; Higgs, D. R.; Wood, W. G. In The Metabolic and Molecular Bases of Inherited Disease, 7th ed.; Scriver, C. R.; Beaudet, A. L.; Sly, W. S.; Valle, D., Eds.; McGraw-Hill: New York, 1995; pp 3417-3484.

2. Wada, Y.; Hayashi, A.; Fujita, T.; Matsuo, T.; Katakuse, I.; Matsuda, H. Biochim. Biophys. Acta 1981, 667, 233-241. 
3. Wada, Y.; Hayashi, A.; Fushimura, M.; Katakuse, I.; Ichihara, T.; Nakabushi, H.; Matsuo, T.; Sakurai, T.; Matsuda, H. Biochim. Biophys. Acto 1983, 749, 244-248.

4. Katakuse, I.; Ichihara, T.; Nakabushi, H.; Matsuo, T.; Matsuda, H.; Wada, Y.; Hayashi, A. Biomed. Mass Spectrom. 1984, 11, 386-390.

5. Pucci, P.; Crestia, C.; Fioretti, G.; Mastrobuoni, A. M.; Pagano, L. Biochim. Biophys. Res. Commun. 1985, 130, 84-90.

6. Castagnola, M.; Landolfi, R.; Rossetti, D. V.; de Angelis, F.; Ceccarelli, S. Anal. Lett. 1986, 19, 1793-1807.

7. Rahbar, S.; Lee, T. D.; Baker, J. A.; Rabinowitz, T.; Asmerom, Y.; Legesse, K.; Ranney, H. M. Hemoglobin 1986, 10, 379-400.

8. Green, B. N.; Oliver, R. W. A.; Falick, A. M.; Shackleton, C. H. L.; Roitman, E.; Witkowska, H. E. In Biological Mass Spectrometry; Burlingame, A. L.; McCloskey, J. A., Eds.; Elsevier: Amsterdam, 1990; pp 129-146.

9. Shackleton, C. H. L.; Falick, A. M.; Green, B. N.; Witkowska, H. E. J. Chromatogr. 1991, 562, 175-190.

10. Wada, Y.; Matsuo, T.; Papayannopoulos, I. A.; Costello, C. E.; Biemann, K. Int. J. Mass Spectrom. Ion Processes 1992, 122, 219-229.

11. Wada, Y. Biol. Mass Spectrom. 1992, 21, 617-624.

12. Ricco, G.; Scaroina, F.; Amprimo, M. C.; Gottardi, E.; Parziale, A.; Alfarano, A.; Camaschella, C. Hematologica 1992, 77, 215-20.

13. Nakanishi, T.; Kishikawa, M.; Shimizu, A.; Hayashi, A.; Inoue, F. J. Mass Spectrom. 1995, 30, 1663-1670.
14. Witkowska, H. E.; Bitsch, F.; Shackleton, C. H. L. Hemoglobin 1993, 17, 227-242.

15. Burlet, O.; Yang, C. Y.; Gaskell, S. J. J. Am. Soc. Mass Spectrom. 1992, 3, 337-344.

16. Burlet, O.; Yang, C. Y.; Guyton, J. R.; Gaskell, S. J. J. Am. Soc. Mass Spectrom. 1995, 6, 242-247.

17. Biemann, K. Biomed. Environ. Mass Spectrom. 1988, 16, 99-111.

18. Wada, Y.; Matsuo, T.; Sakurai, T. Mass Spectrom. Rev. 1989, 8, 379-434.

19. Opfell, R. W.; Lorkin, P. A.; Lehmann, H. J. Med. Gent. 1968, 5, 292-297.

20. Drabkin, D. L. J. Biol. Chem. 1946, 164, 703-723.

21. Rossi-Fanelli, A.; Antonini, E.; Caputo, A. Biochim. Biophys. Acta 1958, 30, 608-615.

22. Shimizu, A.; Hayashi, A.; Yamamura, Y.; Tsugita, A.; Kitayama, K. Biochim. Biophys. Acta 1965, 97, 472-482.

23. Schroeder, W. A.; Shelton, J. B.; Shelton, J. R.; Huynh, V.; Teplow, D. B. Hemoglobin 1985, 9, 461-482.

24. Hirs, C. H. W. J. Biol. Chem. 1955, 219, 611-621.

25. Huddleston, M. J.; Bean, M. F.; Carr, S. A. Anal. Chem. 1993 $65,877-887$.

26. Hunt, D. F.; Yates, J. R., III; Shabanowitz, J.; Winston, S.; Hauer, C. R. Proc. Natl. Acad. Sci. USA 1986, 83, 6233-6237.

27. Hilse, K.; Braunitzer, G. Hoppe-Seylers Z. Physiol. Chem. 1962 329, 113-129.

28. Guidotti, G.; Hill, R. J.; Konigsberg, W. J. Biol. Chem. 1962, 237, 2184-2195. 